\title{
Evaluating Gamer's Cognition and Involvement on the Effectiveness of Gamifying Learning
}

\author{
Chia-Wen Lee ${ }^{1}$, Cheng-Fu Yang ${ }^{2}$, Genmiao Ma ${ }^{3}$, Zhaohua Zhang ${ }^{1 *}$ \\ ${ }^{1}$ School of Humanities, Jinan University, CHINA \\ ${ }^{2}$ Department of Chemical and Materials Engineering, National University of Kaohsiung, TAIWAN \\ ${ }^{3}$ School of Art and Communication, Beijing Normal University, Zhuhai, CHINA
}

Received 11 May 2017 • Revised 18 September 2017 • Accepted 26 September 2017

\begin{abstract}
Video Game-based learning has been an important way for practitioners to gear up for success. Advergames provide an exclusively learning environment in which video gamers pay full attention and thoroughly absorb information without interruption. But still very few studies have been devoted to understanding how individual's selfconstrual and for cognitive product involvement with advergame format influences the evolution of players perception of brand personality. This study was consisted of an experimental study in which a series of advergames was created and two distinct brands: a high and a low cognitively involving products were included as the stimulus. The study identified key measures of effectiveness in the context of 195 American and Chinese participants as subjects were randomly assigned to one of the experimental conditions. This study used $2 \times 2$ factorial between-subjects design. The two factors were individual's self-construal (interdepend and independent) and cognitive product involvement (high and low). The results revealed that the players with interdependent self-construal reported a greater influence on perception of brand personality than the players with independent self-construal. The results further verified an influence of selfconstrual on perception of brand personality in the different product involvement.
\end{abstract}

Keywords: self-construal, product involvement, brand personality

\section{INTRODUCTION}

Advergames provide an exclusive environment in which gamers pay full attention and thoroughly absorb information without interruption. Gamers are invited to participate actively and interact with advertising in fantastical environments to achieve marketing targets by using portable consoles, personal and laptop computers, tablets, or mobile phones (Nelson, 2002). They may catch tremendous numbers of potential brand messages, leading to strongly associate with game attitudes and brand attitudes in the process (Wang, Lee, Mantz \& Hung, 2015). Although there has been a dramatic increase in the number of publications addressing the studies of effects of gamifying learning on brand attitudes (Cauberghe \& Pelsmacker, 2010; Hernandez \& Chapa, 2010; Keng, Chang, Chen \& Chang, 2016; Lee \& Faber, 2007; Lee, Yang \& Hung, 2017; Su \& Hsaio, 2015; Wang et al., 2015), advergame evaluation is still deficient.

In an attempt to explore how and when advergame will be most effective, recent literature suggests that "selfconstrual" may influence individual preference toward brand personality on the effectiveness of advergame (Wang, et al., 2015). Individuals with interdependent self-construal (ITSC) hold a view of self that emphasizes connectedness, relationships, external attributes, and social context, whereas individuals with independent selfconstrual (IDSC) hold a view of self which is associated with separateness, independence, internal attributes, and uniqueness of the individual (Markus \& Kitayama, 1991; Triandis, 1989). In other words, individual with

\footnotetext{
(C) Authors. Terms and conditions of Creative Commons Attribution 4.0 International (CC BY 4.0) apply. 


\section{Contribution of this paper to the literature}

- This study confirms the effectiveness of gamifying learning by testing and controlling the different degrees of gamer's cognitive and involvement.

- This study introduces interdependent and dependent self-construals as individual variables and explores how each impacts the relationship between product involvement and gamifying learning.

- The study strengthens the literature of gamifying learning in varied international contexts and understands the diversity of the ethno-cultural groups by investigating cross-national participants.

interdependent self-construal have a more flexible of relationships; and thus when grouping objects, they can organize information in terms of different types of relationships, whereas individual who are highly independent tend to focus on taxonomic categories and traits (Ji, Zhang, \& Nisbett 2004; Ng \& Houston 2006). Due to selfconstrual reflects the extent to which individuals view themselves either as individualists or collectivists, adopting advertising appeal on individualism or collectivism may affects individuals with interdependent or independent self-construal toward brand (Agrawal \& Maheswaran, 2005). Prior research of self-construal have heavily examined the advertising formats and focused on aspects such as attitudes toward advertising messages and advocated brands (Sung \& Choi, 2011), value express and brand choice (van Baaren \& Ruivenkamp, 2007), preferences of cobrand personality (Monga \& Lau-Gesk, 2007), advertising appeal and generation X (Zhang, 2009), advertising and product involvement (Zhang, Moore \& Moore, 2011). Though theses investigations have delved understand advertising effectiveness, the influence of consumer individual difference have also garnered attention. Specially, Individual with cultural difference and cognitively involving product are suggested to play a crucial factor in disentangling the effective of advertisement (Han \& Shavitt, 1994; Cauberghe \& Pelsmacker, 2010; Zhang, 2009; Zhang et al., 2011).

Advergames, as advertisements, can provide the function of translating brand messages into differentiating individual self-construal (Wang et al., 2015). Cauberghe and Pelsmacker (2010) suggest that product involvement in future research could explore the advanced relationship between advergames and brand attitudes. Despite the acknowledge importance of self-construal in affecting perceived fit of cognitively product involvement, relatively little is known about how marketers can use it to increase consumer individual perception of brand personality on effectiveness of advergame. The purpose of this research is to know whether the differences in individual's selfconstrual, their independent self-construal and interdependent self-construal (IDSC and ITSC), influence the relationship between advergame attitude and embedded brands in the high and the low cognitively involving product. As a result, the difference between IDSC and ITSC in assessing brand personality may be more salient when gamers enjoy their characters smash into a billboard with brand logo or brand logo bounced across their characters in the game.

\section{Product Involvement and Advergame Effectiveness}

The concept of product involvement has influenced brand attitude (e.g., brand personality) in the field. Questor (1997) found that the effect of sponsor brand was positively significant for consumers who go to see races in the stadium, compared with consumers who stay home and watch races on television. Fans who rated high on involvement could more clearly recognize sponsors (and racers) compared to low-involvement fans. Advergames and sponsorship have similar mechanism. When Coca Cola pays to have a billboard displayed at the Federation International de Football Association (FIFA) world cup, it is sport sponsorship. However, when IBM's logo is displayed in Sims, it is advergame. It is possible to apply theories and models from sport sponsorship to advergames.

Although a few studies explored a relationship between brand attitudes and product involvement in advergames (Cauberghe \& Pelsmacker, 2010), Aaker (1996) suggested that consumers with different productinvolvement levels perceive different levels of brand knowledge. Consumers with high involvement in the brand often notice everything about the branded product because they are interested in and have knowledge of the brand. Furthermore, a highly involved product (e.g., those that are high priced, luxury, and infrequently purchased items) may evoke consumers to take a complex decision, whereas, a less involved product (e.g., frequently purchased and durable items) may have difficulty evoking consumers to do purchase it (Zhang et al., 2011). In this study, product involvement plays an important element to explore the effects of self-construal on consumer perception of brand personality in advergames.

\section{Self-Construal and Evaluation of Brand Personality}

Self-construal is a way of information processing that describes how a person defines him- or herself among others (Lee, Aaker \& Gardner 2000; Markus \& Kitayama 1991). Self-construal is a personal trait of an individual but 
also can be influenced by situational factors (Ahluwalia 2008). A person can have either independent or interdependent self-construal when viewing his or her relationships with others. Independent self-construal refers to a view of self in which the self is construed as an autonomous entity reflect the goals of the individuals and is associated with separateness, independence, internal attributes, and uniqueness of the individual, whereas interdependent self-construal is a view of self in which the self is construed as socially embedded and emphasizes connectedness, relationships, external attributes, and social context (Markus \& Kitayama 1991). That means, people with interdependent self-construal usually have a more flexible view of relationships; and thus when grouping objects, they can organize information in terms of different types of relationships, whereas people who are highly independent tend to focus on taxonomic categories and traits (Ji, Zhang, \& Nisbett 2004; Ng \& Houston 2006).

There are two major distinctive ways that each individual, in any culture, constructs the self: independent and interdependent self-construal (Markus \& Kitayama, 1991). People with interdependent self-construal see themselves as part of a group and define themselves with respect to other group members. They also assert that self-construal is based on cultural orientation. Western cultures tend to reward independence and frequently activate the independent self, making it chronically accessible. In contrast, Asian cultures frequently promote the interdependent self, making it chronically accessible. Triandis (1989) argued that more individualistic cultures are characterized by more focus on the private self and less emphasis on the collective self, with increased emphasis on the collective self for less individualistic cultures. People from the West (North American cultures) are thought to have an independent self-construal, which is characterized by separateness from others, uniqueness, and attention to internal attributes, whereas many people from non-Western backgrounds (Asian cultures) are thought to have an interdependent self-construal, which is characterized by connectedness and attention to the social context (Cours, Walker \& Kiesler, 2008).

With respect to advertising appeals, individuals' cultural backgrounds influence the persuasiveness of advertising appeals because individualism-based advertising appeals are more persuasive to individuals with an independent self-construal, whereas collectivism-based advertising appeals are more persuasive to individuals with an interdependent self-construal (Agrawal \& Maheswaran, 2005; Sung \& Choi, 2011; Zhang, 2009). A rally advergames can create a specific virtual world with many gaming stimuli for players to build a relationship between game attitude and brand attitude (Wang et al., 2015), and social feature to facilitate an interaction between player and brand meaning (Lin, 2014; Terlutter \& Capella, 2013). Advergames may tend to foster collectivistic appeal rather than individualistic appeal. According Zhang (2009), collectivistic advertising appeal can more persuade to consumer with ITSC. It is also reasonable to assume that gamers with INSC are more easily assessable brand meaning when they play advergame. As a result, advergame should induce more positive brand personality attitude in those ITSC players than those IDSC players. The first hypothesis is as follows:

H1: Compared of gamers with IDSC, gamers with ITSC will have higher influences on the perceived brand personality on the effectiveness of advergame.

The application of an individual's self-construal also includes product involvement. Han and Shavitt (1994) found that low-involvement products (e.g., durable products) are more favorable when the advertising appeal is congruent with consumers' cultural background. Aaker's (2000) results exhibited the same finding: that highly culturally congruent advertising increases appeal and more favorable attitudes under low-involvement conditions. Self-construal is an important factor in influencing consumers' attitudes toward brand. Individualist appeals are a good advertising strategy to induce consumers' attitudes toward a brand (Zhang, 2009). Zhang et al. (2011) discovered that when promoting low-involvement products, advertising appeals are congruent when individuals' self-construal generates more favorable attitudes toward a brand. Advergames, like advertising, are promotional tools focused on individualism. That is, the study assumes individuals with ITSC generate more favorable attitudes toward brand personality in advergames than those with IDSC when promoting low-involvement product.

On the other hand, previous studies on the effectiveness of advertising reveal that individualistic advertising appeals when promoting high-involvement products do not generate favorable attitudes toward brands for consumers (Zhang, 2009; Zhang et al., 2011). It is possible, because consumers may do much more research on highinvolvement products, that they are not easily influenced by advertising. This study therefore proposes the second and the third hypothesis:

H2: When exposed to advergame for a low product involvement category, gamers with ITSC will generate more favorable attitude toward perception of brand personality than those with IDSC.

H3: When exposed to advergame for a high product involvement category, gamers with ITSC will not generate more favorable attitude toward perception of brand personality than those with IDSC. 


\section{METHOD}

\section{Design and Procedure}

This study employed a 2 (self-construal: interdependent versus independent) X 2 (product involvement: high versus low) between-subjects design. Within each group in each country, participants were randomly assigned to one of the three conditions: high cognitive involving advergame, low cognitive involving advergame.

\section{Participants}

The overall purpose of this research was to uncover the extent to which advergames influences consumers' sense of brand personality. They study collects data from 195 male gamers who had ever played video games participated in the experiment. A pool of respondents was made up of 50.3\% Chinses and 49.7\% Americans. They were recruited and interviewed in the computer laboratory at the campus and received cash incentive (hourly wage) for their cooperation. Participants were randomly assigned to one of two groups. First they played a racingcar game in five minutes and were exposed to an embedded brand placed in the welcome screen, in the starting of the game, in the peripheral of a racing car. Then they were asked to evaluate their perception of brand personality.

\section{Brand personality}

Brand personality was assessed by asking participants to rate how they felt about the brand in the game. Aaker (1997) developed the five dimensions of brand personality (sincerity, excitement, competence, sophistication, and ruggedness) in 15 facets that encompassed 42 items. Participants rated the score on 5-point Likert-type scale ranging from not at all descriptive (1) to extremely descriptive (5). For example, for sincerity, the brand was identified by responses of down-to-earth and is family-oriented (American version $\mathrm{a}=.92$ and Chinese version $\mathrm{a}=.95$ ).

\section{Product involvement}

Participants' product involvement as a moderating role was measured by identifying frequently purchased and infrequently purchased items because consumers may use different processes of decision making in high-involved product (infrequently purchased items) and low-involved product (frequently purchased items; Zhang et al., 2011). Using a content analysis sample (Wang et al., 2015), this study selected from each country example of brands either BMW and McDonald's to represent a high and a low cognitively involving product. Compared with consumers usually taking longer process to make a purchase decision on BMW cars, they buy McDonald's food without such considered thinking.

\section{Self-construal}

The study included an American group and a Chinese group according to Cours et al. (2008) assertion that American culture is closer to independent self-construal, whereas Asian cultures are closer to interdependent selfconstrual.

\section{RESULTS}

The purpose of this study was to examine whether the perception of brand personality was influenced the effects of two variables in the racing-car advergame. This study expected that was a significant difference between ITSC and IDSC in the experiment. In addition, this study was concerned with an interaction between ITSC and cognitively low involving product (Hypotheses 2). Finally, the study questioned that no effect of IDSC and cognitively high involving product in the perception of brand personality in the experiment (Hypothesis 3 ). Independent $t$ test was used to verify that there was a significant difference between IDSC and ITSC in the perception of brand personality. Overall, the result revealed that the perception of brand personality were influenced by a significant difference between IDSC and ITSC $\left(\mathrm{M}_{\mathrm{ITSC}}=3.50, \mathrm{M}_{\mathrm{IDSC}}=3.15, \mathrm{t}(194)=3.92, \mathrm{p}=.000\right)$ that supported hypotheses 1, respectively. See Table 1.

A two-way ANOVA was used to verify that there was a significant interaction effect of low involvement product and self-construal on the perception of brand personality. The results displayed the perception of brand personality were influenced by a significant interaction between ITSC and cognitively low involving product ( $\mathrm{F}(1$, 194) $=5.80, p=.017)$. See Figure 1 . 

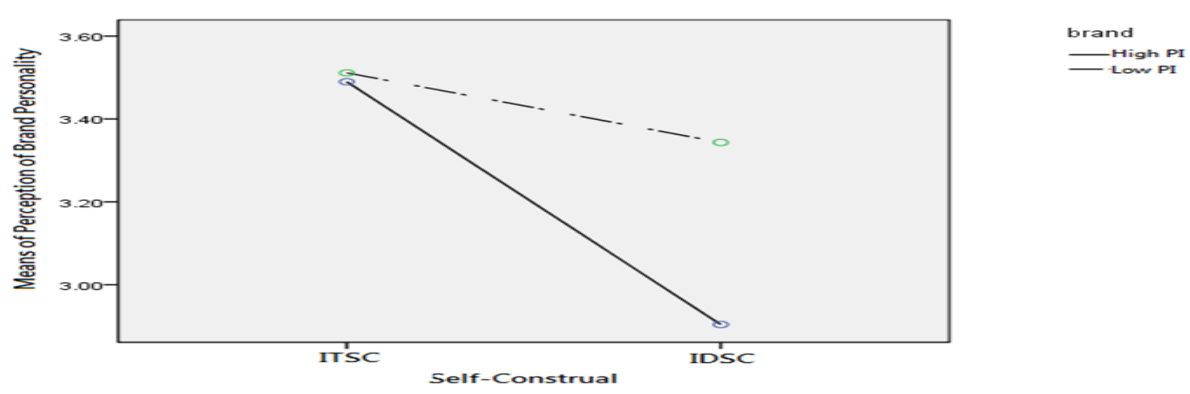

Figure 1. Interaction effect between self-construal and product Involvement Notes: ITSC=interdependent self-construal; IDST=independent self-construal

Table 1. Influence of Self-Construal and Cognitive Product Involvement on the Perception of Brand Personality

\begin{tabular}{cccccc}
\hline Low PI & ITSC & IDSC & Total & F/t & P \\
\hline High PI & $\begin{array}{c}3.49 \\
(\mathrm{n}=49)\end{array}$ & $\begin{array}{c}2.90 \\
(\mathrm{n}=42)\end{array}$ & $\begin{array}{c}3.22 \\
(\mathrm{n}=91)\end{array}$ & 19.69 & $0.000^{*}$ \\
\hline Total & $\begin{array}{c}3.51 \\
(\mathrm{n}=49)\end{array}$ & $\begin{array}{c}3.34 \\
(\mathrm{n}=55)\end{array}$ & $\begin{array}{c}3.42 \\
(\mathrm{n}=104)\end{array}$ & 2.16 & 0.144 \\
\hline
\end{tabular}

Notes: PI Product Involvement; ITSC=interdependent self-construal; IDST=independent self-construal

Furthermore, ANOVA was used to find detailed information about hypothesis 2 and 3. Simple main effect tests further showed that cognitively low involving product was viewed more favorable on the perception of brand personality by the players with ITSC $\left(\mathrm{M}_{\mathrm{ITSC}}=3.49, \mathrm{M}_{\mathrm{IDSC}}=2.90, \mathrm{~F}(1,89)=19.69, \mathrm{p}=.000\right)$. Additionally, as this inferred there was no difference in evaluation for the players with IDSC for cognitively high involving product on the perception of brand personality $\left(\mathrm{M}_{\mathrm{ITSC}}=3.51, \mathrm{M}_{\mathrm{IDSC}}=334, \mathrm{~F}(1,103)=2.16, \mathrm{p}=.144\right)$, Hypothesis 3 was supported. See Table 1.

\section{DISCUSSIONS AND CONCLUSIONS}

This study investigated the influence of the gamer's self-construal on the effectiveness of brand personality in the context of a high and a low cognitively involving products as well as assumed that the racing-car advergame would have collectivistic appeal and a greater influence on perception of brand personality to gamers with ITSC than for those players with IDSC. Interesting results regarding the influence of the variables toward perception of brand personality were found.

Overall, the results revealed that the players with ITSC reported a greater influence on brand personality than the players with IDSC. This is congruent to the results of previous studies (Agrawal \& Maheswaran, 2005; Sung \& Choi, 2011; van Baaren \& Ruivenkamp, 2007; Wang et al., 2015; Zhang et al, 2011) that individual preferred advertising appeal that are congruent with their self-construal to influence toward brand attitude. A reason might account for the differentiation of perception of brand personality for the players with different levels of selfconstrual in the effectiveness of advergame. Due advergames provide highly interactive nature to induce a player to pay more attention, find more differentiation, and organize more information, marketing practitioners can adopt the strategy of advergame to precisely lock market segmentation and to raise their brands toward individual with ITSC in the competitive business environment.

The results further verified an influence of self-construal on perception of brand personality in the different product categories. The study assumed that the gamers with ITSC reported greater influence of perception of brand personality in the effectiveness of advergame when promoting a low-involvement product than the players with IDSC. The interactive effects of self-construal and product involvement on brand personality in the advergame were found that self-construal played crucial element and the influence was different when associated with differentiated cognitively produce involvement. Specifically, when exposed to advergame for a low product involvement category, gamers with ITSC showed more favorable attitude toward perception of brand personality than those with IDSC. Additionally, it was predicted that the players with self-construal would be less likely to influence processing for an advergame with high cognitively involving product. These results were consistent with previous findings showing that effectiveness of advertising appeal dep ended on consumers' self-construal and product involvement (Zhang et al., 2011). Therefore, when promoting for a low involving product, advergame may be better targeted to specific market segmentation. For instance, Race Driver Grid, a famous racing game developed 
and published by Codematers for many video game platforms, may be a good medium to promote perception of McDonald's brand personality for Chinses gamers whereas it may be not easily to raise in players perception of BMW brand personality. This investigation should help market practitioners further explore the effectiveness of advergame as part of a marketing system.

Although this study provides much valuable insight into the influence for a gamer's perception of brand personality on effectiveness of advergame, there are several limitations and suggestions for future research. Because this study ignores consumer gender differences and lab experiments of major limitations, future research should be considered with heterogeneous consumers samples and take other methodologies such as field experiment to provide more comprehensive understandings on effectiveness of advergame.

The effectiveness of a racing-car advergame may not able to be inferred across different types of games or media. For instance, embedded brands in mass multiplayer online role-playing games (MMORPG) may have different findings. The effectiveness may be differentiated by other communication tools such as mobile phone, movies, television, and books. Future research is needed to explore the effectiveness of those communication tools due to executing multiple marketing strategies of advertising, sponsorship, or product placement that may provide greater synergies than a single strategy. The potential of above marketing strategies on perception of brand personality clearly needs further exploration.

\section{REFERENCES}

Aaker, D. A. (1996). Measuring brand equity across products and markets. California Management Review, 38, 102120.

Aaker, J. L. (1997). Dimensions of brand personality. Journal of Marketing Research, 34, 347-356.

Agrawal, N., \& Maheswaran, D. (2005). The effects of self-construal and commitment on persuasion. Journal of Consumer Research, 31, 841-849.

Ahluwalia, R. (2008). How far can a brand stretch? Understanding the role of self-construal. Journal of Marketing Research, 45(3), 337-350.

Cauberghe, V., \& Pelsmacker, P. D. (2010). Advergames: The impact of brand prominence and game repetition on brand responses. Journal of Advertising, 39(1), 5-18. Cours, D., Walker, K., \& Kiesler, T. (2008). Self-construal, reference groups, and brand purchase behavior. Advances in Consumer Research, 8, 469-474.

Han, S. P., \& Shavitt, S. (1994). Persuasion and culture: Advertising appeals in individualistic and collectivistic societies. Journal of Experimental Social Psychology, 30(4), 236-350.

Hernandez, M. D., \& Chapa, S. (2010). Adolescents, advergames and snack foods: Effects of positive affect and experience on memory and choice. Journal of Marketing Communications, 16, 59-68.

Ji, L. J., Zhang, Z., \& Nisbett, R. E. (2004). It is culture, or is it language? Examination of language effects in crosscultural research on categorization. Journal of Personality and Social Psychology, 87(1), 57-65.

Keng, C., Chang, W., Chen, C., \& Chang, Y. (2016). Mere virtual presence with product experience affects brand attitude and purchase intention. Social Behavior and Personality, 44(3), 431-444. https://doi.org/10.2224/sbp.2016.44.3.431

Lee, A. Y., Aaker, J. L., \& Gardner, W. L. (2000). The pleasures and pains of distinct self-construals; The role of interdependence in regulatory focus. Journal of Personality and Social Psychology, 78(6), 1122-1134.

Lee, C. W., \& Aiken, D. K. (2010). Changing brand associations in Taiwan: Nike's sponsorship of high school basketball. Journal of Sponsorship, 3(3), 249-259.

Lee, C., Yang, C., \& Hung, H. (2017). Evaluating Game-Brand Congruity and Flow on Brand Personality by Using Gamifying Learning. EURASIA Journal of Mathematics, Science and Technology Education, 13(7), 3083-3097.

Lee, M., \& Faber, R. J. (2007). Effects of product placement in on-line games on brand memory: A perspective of the limited-capacity model of attention. Journal of Advertising, 36, 75-90.

Lin, L. Y. (2010). A study on the relationship of consumer personality trait brand personality and brand loyalty: An example of toys and video games buyers. Journal of Product and Brand Management, 19, 4-17.

Markus, H. R., \& Kitayama, S. (1991). Culture and the self: implications for cognition, emotion, and motivation. Psychological Review, 98(2), 224-253.

Markus, H., \& Kitayama, S. (1991). Culture and the self: Implications for cognition, emotion and motivation. Psychological Review, 98, 224-253.

Monga, A. B., \& Lau-Gesk, L. (2007). Blending cobrand personalities: An examination of the complex self. Journal of Marketing Research, 44, 389-400. 
Ng, S., \& Houston, M. J. (2006). Exemplars or beliefs? The impact of self-view on the nature and relative influence of brand association. Journal of Consumer Research, 32(4), 519-529.

Questor, P. G. (1997). Awareness as a measure of sponsorship effectiveness: The Adelaide formula one grand prix and evidence of incidental ambush effects. Journal of Marketing Communication, 3, 1-20.

Shah, J., Higgins, T. E., \& Friedman, R. S. (1998). Performance incentives and means: How regulatory focus influence goal attainment. Journal of Personality and Social Psychology, 74, 285-293.

Su, C. H \& Hsaio, K. C. (2015). Developing and Evaluating Gamifying Learning System by Using Flow-Based Model. Eurasia Journal of Mathematics, Science \& Technology Education, 11(6), 1283-1306.

Sung, Y., \& Choi, S. M. (2011). Increasing power and preventing pain: The moderating role of self-construal in advertising message framing. Journal of Advertising, 40(1), 71-85.

Terlutter, R., \& Capella, M. L. (2013). The gamification of advertising: Analysis and research directions of in-gaming advertising, advergames, and advertising in social network games. Journal of Advertising, 42, 95-112.

Triandis, H. C. (1989). The self and social behavior in differing cultural contexts. Psychological Review, 96, 506-520.

van Baaren, R. B., \& Ruivenkamp, M. (2007). Self-construal and values express in advertising. Social Influence, 2, 136-144.

Wang, L., Lee, C. W., Mantz, T. K., \& Hung, H. C. (2015). Effects of Flow and Self-Construal on Brand Personality in Racing Advergame. Social Behavior and Personality, 43 (4), 1181-1192.

Zaichkowsky, J. L. (1994). The personal involvement inventory: Reduction, revision and application to advertising. Journal of Advertising, 23(4), 59-70.

Zhang, L. (2009). The effect of advertising appeals in activating self-construals: A case of bicultural Chines Generation X consumers. Journal of Advertising, 38(1), 63-82.

Zhang, L., Moore, M., \& Moore, R. (2011). The effect of self-construals on the effectiveness of comparative advertising. Marketing Management Journal, 21(1), 195-206.

Zigmond, D., \& Stipp, H. (2010). Assessing a new advertising effect measurement of the impact of television commercials on Internet search queries. Journal of Advertising Research, 50(2), 162-168.

\section{http://www.ejmste.com}

